\title{
The Prevalence and Risk Factors of Microalbuminuria in Hypertensive Patients under Current Medical Treatment
}

\author{
Hidehiko Hara ${ }^{1}$, Kenichi Kougami ${ }^{2}$, Kotaro Shimokawa ${ }^{3}$, Shunichi Nakajima ${ }^{4}$, \\ Rintaro Nakajima ${ }^{5}$, Ryoichi Nakamura ${ }^{6}$, Koichi Hirahata ${ }^{7}$, \\ Hajime Hoshi $^{8}$ and Masato Nakamura ${ }^{1}$
}

\begin{abstract}
Objective A link between urinary albumin excretion and an increased incidence of cardiovascular mortality has already been demonstrated. However, the reported prevalence of microalbuminuria (MAU) in patients with hypertension is highly variable. We therefore aimed to conduct a cross-sectional multicenter study to investigate the prevalence of urinary albumin excretion in treated hypertensive patients in our current practice. Methods A total of 1,258 hypertensive patients were enrolled in this study. Patients with macroalbuminuria were excluded. The concentrations of urinary microalbumin and creatinine were measured. Urinary albumin excretion was expressed as the ratio of albumin to creatinine excretion.

Results The mean systolic and diastolic blood pressures were $130.9 \pm 12.7 \mathrm{mmHg}$ and $74.7 \pm 8.9 \mathrm{mmHg}$, respectively. The overall prevalence of MAU was $42.8 \%$, and it was observed in $35.8 \%$ of patients treated with a single medication. Patients with polyvascular disease exhibited a higher prevalence of MAU compared with patients with monovascular disease. The factors related to the presence of MAU included the estimated glomerular filtration rate (eGFR), systolic blood pressure, and glycated hemoglobin (HbA1c) level (odds ratios [ORs] of $0.988,1.026$, and 1.371 , respectively).

Conclusion The present study showed that the prevalence of MAU among hypertensive patients was $42.8 \%$, even in patients whose blood pressure was relatively well controlled. Additionally, the eGFR, systolic blood pressure, and HbA1c level are risk factors for the development of MAU. These findings suggest that a substantial number of hypertensive patients have MAU and highlight the importance of strictly controlling these factors to improve patient prognosis.
\end{abstract}

Key words: microalbuminuria, hypertension, chronic kidney disease

(Intern Med 53: 1275-1281, 2014)

(DOI: 10.2169/internalmedicine.53.2110)

\section{Introduction}

Epidemiological studies have shown that chronic kidney disease (CKD) is an independent risk factor for cardiovascular mortality and morbidity and that the proportion of patients with CKD has recently increased (1-3). Because coronary artery disease (CAD) remains the primary cause of mortality, much attention must be paid to the prevention and treatment of CKD. One important point regarding CKD is that the risk of cardiovascular disease increases in both patients with end-stage renal disease (ESRD) and those with early-stage CKD (G1, G2) $(2,4,5)$. Therefore, providing early detection tests and appropriate treatment for CKD is clinically meaningful. Treatment should be administered at an earlier stage to achieve a better outcome; however, the early stage of CKD is unlikely to be diagnosed in a timely manner and can be easily overlooked. Numerous studies

\footnotetext{
${ }^{1}$ Division of Cardiovascular Medicine, Toho University, Ohashi Medical Center, Japan, ${ }^{2}$ Kougami Clinic, Japan, ${ }^{3}$ Yutenji Medical Clinic, Japan, ${ }^{4}$ Nakajima Clinic, Japan, ${ }^{5}$ Nakajima Medical \& Pediatric Clinic, Japan, ${ }^{6}$ Komazawa Jin Clinic, Japan, ${ }^{7}$ Hirahata Clinic, Japan and ${ }^{8}$ Hoshi Clinic, Japan

Received for publication November 24, 2013; Accepted for publication February 23, 2014

Correspondence to Dr. Hidehiko Hara, harahide@oha.toho-u.ac.jp
} 
have demonstrated that microalbuminuria (MAU), a powerful predictor of glomerular injury, is also a predictor for the development of renal and cardiovascular complications (6-10). This association is independent of the effects of widely accepted cardiovascular risk factors. Furthermore, the LIFE study demonstrated that reducing the level of urinary albumin excretion during treatment translated into a reduced incidence of cardiovascular events (11). However, the reported prevalence of MAU is highly variable among studied populations, ranging from 7 to $58.4 \%$ (12-14). This variation may be explained by differences in prescribed drugs and population characteristics. In particular, pharmacological therapies that have beneficial effects on blood pressure control may decrease the development of MAU. Therefore, we sought to investigate the prevalence of MAU and risk factors in Japanese hypertensive patients under current medical treatment.

\section{Materials and Methods}

The Jonan Irbesartan Microalbuminuria Study (JIMS) investigators conducted a cross-sectional, multicenter, cohort study to assess the prevalence of urinary albumin excretion in treated hypertensive patients under current medical therapy. Seven medical clinics and university-affiliated hospitals in the Jonan area of Tokyo participated in the present study, which was performed in a primary care setting. Consecutive patients with hypertension who visited each clinic/hospital were enrolled. The study was initiated in July 2009, and a total of 1,308 hypertensive patients were enrolled by the end of August 2010. The exclusion criteria included secondary hypertension, renal insufficiency with a plasma creatinine concentration $>2.0 \mathrm{mg} / \mathrm{dL}$, and persistent macroproteinuria on conventional dipstick tests of spot urine samples (positive $\geq 2+$ ). Patients with acute fever or concomitant urinary tract infection, who had engaged in strenuous physical activity within the preceding 24 hours, and female participants who were pregnant or menstruating were excluded due to the likely outcome of false-positive results. The patients' systolic and diastolic blood pressures were measured using a mercury manometer placed on the right arm of the seated subject after resting in a seated position for at least five minutes before measurement. Hypertension was defined as an average blood pressure $>140 / 90 \mathrm{mmHg}$ on at least two different occasions during routine examination. Treated diabetes was defined as diabetes treated with an oral hypoglycemic or insulin. Subjects with a fasting blood sugar level $>126 \mathrm{mg} / \mathrm{dL}$, a random blood sugar level >200 mg/dL, or a glycated hemoglobin $(\mathrm{HbA} 1 \mathrm{c})$ value $>6.1 \%$ were also classified as diabetic. Hypercholesterolemia was defined as a total cholesterol level $>240 \mathrm{mg} / \mathrm{dL}$. Obesity was defined as a body mass index (BMI) $>25 \mathrm{~kg} / \mathrm{m}^{2}$, calculated as the body weight in kilograms divided by the square of the height in meters. The study was approved by the medical ethics committee at Toho University Ohashi Medical Center (Approval number: $21-5)$, and all patients provided their informed con- sent.

\section{Laboratory findings}

The patients' serum creatinine levels were measured using an enzymatic method. The glomerular filtration rate (GFR) was estimated (eGFR) based on the adjusted serum creatinine level using the simplified equation developed from the Modification of Diet in Renal Disease (MDRD) study as follows: GFR $\left(\mathrm{mL} / \mathrm{min} / 1.73 \mathrm{~m}^{2}\right)=186.3 \times$ (serum creatinine) $-1.154 \times$ age $^{-0.203} \times(0.742$ for female subjects) (15). Freshly voided urine was obtained, and dip stick urine tests were performed. Proteinuria was evaluated semiquantitatively $(-, \pm$, and +$)$.

\section{Quantitative measurement of the urinary albumin-to- creatinine ratio (UACR)}

Each patient's urine albumin level was measured immediately after urine collection using the CLINITEK ${ }^{\circledR}$ Microalbumin 2 (Siemens Healthcare Diagnostics Inc., Erlangen, Germany). The CLINITEK urinary chemistry analyzer is a highly sensitive, portable, reflectance photometer-based, purely chemical albumin test strip device that assesses dye binding by albumin. The urinary dip reagent strips can be used to detect an albumin concentration between 10 and 150 $\mathrm{mg} / \mathrm{L}$ in addition to simultaneously measuring the urinary creatinine concentration (16). The level of urinary albumin excretion was expressed as the ratio of albumin to creatinine excretion. The cutoff values for the presence of MAU and macroalbuminuria were $30 \mathrm{mg} / \mathrm{gCr}$ and $300 \mathrm{mg} / \mathrm{gCr}$, respectively.

\section{Statistical analysis}

All data were sent to the professional statistical analysis department of a company independent from this study that deals with medical business. Continuous variables were expressed as the mean \pm standard deviation, and categorical variables were expressed as frequencies. For comparisons between groups, Student's $t$-tests were used to evaluate differences in means, and $\chi^{2}$ tests were used to evaluate differences in proportions. Regarding the prevalence of microalbuminuria according to age, bivariate $\chi^{2}$ tests were used to generate a cross-table of age $\times$ CLINITEK test results. Univariate $\chi^{2}$ tests were used for each stage of CKD to clarify the relationship between CKD staging and the prevalence of MAU. To test the independent relationships between MAU and the clinical variables, potential factors were selected using a univariate regression analysis, and the selected variables were assessed in a multiple logistic regression analysis model using a stepwise selection method (backward elimination method). The relationships between the risk factors and the incidence of MAU were also studied using a multiple regression method adjusted for sex and CKD stages 1 and 2 . All statistical analyses were performed using the SPSS12.0 software program (SPSS Inc., Chicago, USA). A significant difference was defined as $\mathrm{p}<0.05$. 
Table 1. Baseline Patient Demographics

\begin{tabular}{|c|c|}
\hline & $n=1258)$ \\
\hline Age(years) & $70.0 \pm 11.5$ \\
\hline male $(\%)$ & $753(59.9)$ \\
\hline Height $(\mathrm{cm})$ & $160.5 \pm 9.4$ \\
\hline Body weight(kg) & $61.8 \pm 12.1$ \\
\hline $\operatorname{BMI}\left(\mathrm{kg} / \mathrm{m}^{2}\right)$ & $23.9 \pm 3.5$ \\
\hline Systolic BP(mmHg) & $130.9 \pm 12.7$ \\
\hline Diastolic BP(mmHg) & $74.7 \pm 8.9$ \\
\hline Diabetes Mellitus & $452(35.9 \%)$ \\
\hline \multicolumn{2}{|l|}{ Laboratory findings } \\
\hline $\mathrm{WBC}(\mu \mathrm{L})$ & $6143 \pm 1629$ \\
\hline $\mathrm{Hb}(\mathrm{g} / \mathrm{dL})$ & $14.0 \pm 1.6$ \\
\hline Hct $(\%)$ & $40.7 \pm 4.4$ \\
\hline $\operatorname{PLT}\left(\mathrm{x} 10^{4} / \mu \mathrm{L}\right)$ & $21.4 \pm 6.0$ \\
\hline $\mathrm{eGFR}\left(\mathrm{mL} / \mathrm{min} / 1.73 \mathrm{~m}^{2}\right)$ & $65.2 \pm 19.1$ \\
\hline $\mathrm{TP}(\mathrm{g} / \mathrm{dL})$ & $7.603 \pm 0.59$ \\
\hline AST(IU/L) & $23.3 \pm 10.3$ \\
\hline ALT(IU/L) & $21.609 \pm 21.2$ \\
\hline LDH(IU/L) & $373.5 \pm 125.258$ \\
\hline yGTP(IU/L) & $31.6 \pm 46.5$ \\
\hline $\mathrm{BUN}(\mathrm{mg} / \mathrm{dL})$ & $17.2 \pm 8.5$ \\
\hline $\mathrm{Cr}(\mathrm{mg} / \mathrm{dL})$ & $0.90 \pm 0.53$ \\
\hline $\mathrm{UA}(\mathrm{mg} / \mathrm{dL})$ & $5.6 \pm 1.4$ \\
\hline $\mathrm{T}-\mathrm{CHO}(\mathrm{mg} / \mathrm{dL})$ & $188.2 \pm 32.0$ \\
\hline $\mathrm{TG}(\mathrm{mg} / \mathrm{dL})$ & $135.8 \pm 83.4$ \\
\hline HDL-CHO(mg/dL) & $58.9 \pm 17.0$ \\
\hline $\mathrm{LDL}-\mathrm{CHO}(\mathrm{mg} / \mathrm{dL})$ & $103.5 \pm 27.0$ \\
\hline $\mathrm{GLU}(\mathrm{mg} / \mathrm{dL})$ & $115.2 \pm 38.1$ \\
\hline HbA1c(\%; JDS) & $5.7 \pm 0.8$ \\
\hline
\end{tabular}

\section{CKD staging}

CKD stage1 $(\mathrm{eGFR} \geq 90)$

CKD stage2 $(60 \leq \mathrm{eGFR}<90)$

CKD stage $3(30 \leq \mathrm{eGFR}<60)$

CKD stage $4(15 \leq \mathrm{eGFR}<30)$

CKD stage5 $(\mathrm{eGFR}<15)$

$117(9.27 \%)$

$664(52.86)$

$433(34.40)$

$37(2.95 \%)$

$7(0.52 \%)$

\section{Medical treatments}

only diet \& exercise

single CB

single ARB

single ACEI

single diuretics

single $B$ blocker

Single combination drug

others

2 medications with ARB

3 medications with ARB

4 medications (ARB, CB, diuretics, $B$ blocker)

more than 5 medications

BMI: body mass index, BP: blood pressure, WBC: white blood cell, Hb: hemoglobin, Hct: hematocrit, PLT: platelet, eGFR: estimated glomerular filtration rate, TP: total protein, AST: aspartate aminotransferase, ALT: alanine aminotransferase, LDH: lactate dehydrogenase, YGTP: gamma-glutamyl transpeptidase, BUN: blood urea nitrogen, $\mathrm{Cr}$ : creatinine, UA: uric acid, T-CHO: total cholesterol TG: triglyceride, HDL-CHO: high density lipoprotein cholesterol, LDL-CHO: low density lipoprotein cholesterol, GLU: glucose, HbA1c: hemoglobin A1c, JDS: japan diabetes society, CKD: chronic kidney disease, CB: calcium channel blocker, ARB: angiotensin II receptor blocker, ACEI: angiotensin converting enzyme inhibitor

\section{Results}

\section{Patient demographics}

A total of 1,308 patients were enrolled in the present study. Fifty patients were excluded from the analysis due to the presence of macroalbuminuria on examination. Consequently, 1,258 patients were included in the final analysis. The demographics of the registered patients are shown in Table 1. The mean age was $70.0 \pm 11.5$ years, and $59.9 \%$ of the subjects were men. The mean systemic blood pressure was $130.9 \pm 12.7 / 74.7 \pm 8.9 \mathrm{mmHg}$, and the proportion of patients with obesity $\left(\mathrm{BMI}>25 \mathrm{~kg} / \mathrm{m}^{2}\right)$ was $30.6 \%$. The mean HbA1c level (Japan Diabetes Society [JDS] value) was 5.7 0.79 . In total, the proportions of subjects with stage 1 (eGFR $>90 \mathrm{~mL} / \mathrm{min} / 1.73 \mathrm{~m}^{2}$ ), stage 2 (eGFR $60-89 \mathrm{~mL} / \mathrm{min} /$ $\left.1.73 \mathrm{~m}^{2}\right)$, stage $3\left(\right.$ eGFR $\left.30-60 \mathrm{~mL} / \mathrm{min} / 1.73 \mathrm{~m}^{2}\right)$, stage 4 (eGFR $15-30 \mathrm{~mL} / \mathrm{min} / 1.73 \mathrm{~m}^{2}$ ), and stage 5 (eGFR $<15 \mathrm{~mL} /$ $\min / 1.73 \mathrm{~m}^{2}$ ) disease were $9.27 \%, 52.86 \%, 34.40 \%, 2.95 \%$, and $0.52 \%$, respectively. A total of $47.72 \%$ of the patients were treated with single antihypertensive drugs, and the remaining patients were treated with multiple medications. The majority of patients treated with monotherapy were prescribed angiotensin receptor blockers (ARBs, 19.56\%), angiotensin-converting enzyme inhibitors (ACEIs, 3.98\%), or calcium channel blockers $(15.82 \%)$.

\section{Prevalence of urine albumin excretion}

The study cohort included subjects with conventional spot urine dip stick test results of \pm and $+(5.8 \%$ and $5.0 \%$, respectively). The prevalence of MAU in these subjects is shown in Table 2. Not all patients with positive urinary dip stick protein tests $( \pm$ or + ) had positive Clinitek MAU tests. The rate of positive Clinitek MAU results was $85.7 \%$ among the patients with positive urinary dip stick protein test results.

In addition, the Clinitek urinary dipstick test revealed that $42.8 \%$ of the total study population had evidence of MAU, with a prevalence rate of $38.1 \%$ among the subjects with negative proteinuria results on ordinary urine dip stick tests. MAU was prevalent across all age groups, and the proportion of subjects with MAU increased in association with age and CKD stage (Fig. 1, 2).

\section{Relationships between MAU and clinical variables}

Table 3 presents the profiles of the subjects with MAU. There was a significant decrease in the incidence of MAU among the patients treated with a single ARB or ACEI or a combination agents, most of which included ARBs. Regarding the relationship between the prevalence of MAU and vascular events, patients with peripheral artery disease (PAD) were more likely to be positive for MAU. In addition, patients with polyvascular disease tended to be positive for MAU; however, no statistical differences were observed. A univariate logistic regression analysis revealed that the following factors were associated with the presence of MAU: age, male gender, height, body weight, systolic blood pressure, eGFR, blood urea nitrogen (BUN), plasma glucose level, HbAlc level, a diagnosis of diabetes, and the presence of PAD (Table 4). A multiple logistic regression model with a stepwise selection method (backward elimination) identi- 
Table 2. The Prevalence of MAU and Spot Urine Dip Stick Test

\begin{tabular}{crrrrrrr}
\hline & & \multicolumn{3}{c}{ Clinitek (-) } & \multicolumn{3}{c}{ Clinitek (+) } \\
\cline { 3 - 8 } & & \multicolumn{1}{c}{ number } & ratio & $\begin{array}{c}\text { negative } \\
\text { rate }\end{array}$ & number & ratio & $\begin{array}{c}\text { rate } \\
\text { rative }\end{array}$ \\
\hline qualitative & \pm & 15 & $1.19 \%$ & $20.5 \%$ & 58 & $4.61 \%$ & $79.5 \%$ \\
U-TP & + & 9 & $0.72 \%$ & $14.3 \%$ & 54 & $4.29 \%$ & $85.7 \%$ \\
\hline $\begin{array}{c}\text { total number for } \\
\text { analysis }\end{array}$ & & 1258 & $100.00 \%$ & & 1258 & $100.00 \%$ & \\
\hline
\end{tabular}

MAU: microalbuminuria

U-TP: urinary total protein

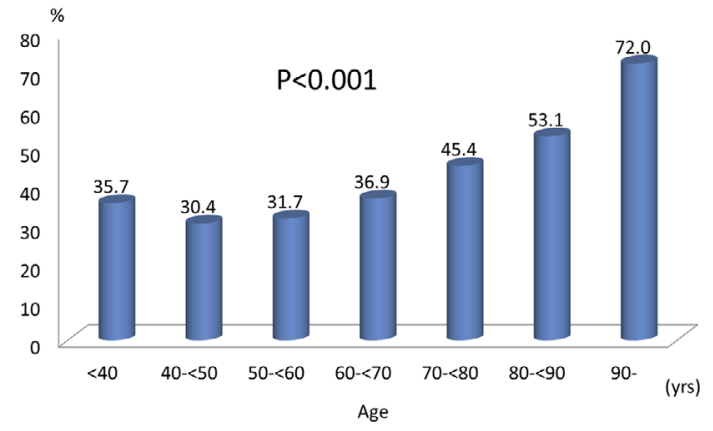

Figure 1. Prevalence of MAU according to age. MAU was prevalent across all age groups and increased with age. MAU: microalbuminuria

fied eGFR, systolic blood pressure, and HbA1c level as independent factors. The risk of developing MAU increased 1.026 times with each $1-\mathrm{mmHg}$ increase in systolic blood pressure. Conversely, a $0.1-\mathrm{mL} / \mathrm{min} / 1.73 \mathrm{~m}^{2}$ increase in eGFR was associated with a 0.988 -fold decrease in the risk of MAU (Table 5). Systolic blood pressure, HbA1c level, and eGFR were identified to be risk factors of MAU positivity according to a multivariate regression analysis adjusted for sex.

\section{Discussion}

The present study was an observational study of patients with treated hypertension in real-world practice in Japan. The main findings of the present study are as follows: 1) the prevalence of albuminuria was $42.8 \%$; 2) the presence and absence of dip stick proteinuria were $85.7 \%$ and $38.1 \%$ in patients with MAU, respectively; and 3) the independent factors for MAU were eGFR, systolic blood pressure, and HbA1c. It has been shown that albuminuria is more sensitive than proteinuria in detecting CKD; therefore, screening programs to identify the disease before the clinical phase are meaningful, but there have been no direct comparisons between proteinuria and MAU in terms of utility.

In the present study, MAU was detected in $38.1 \%$ of the spot urine samples in patients with negative dip stick proteinuria results. Therefore, the present study confirmed the findings of a previous study showing the relationship between ordinary dip stick proteinuria and MAU (17).

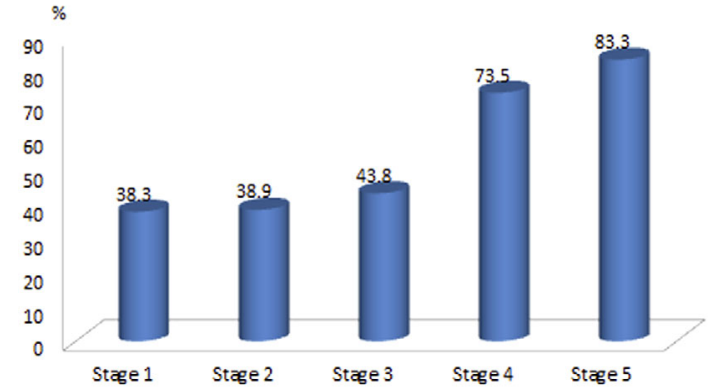

Figure 2. CKD stages and the prevalence of MAU. MAU was prevalent across all CKD groups and increased in association with the CKD stage. CKD: chronic kidney disease, MAU: microalbuminuria. Stage 1, $p=0.016$; Stage 2, p<0.001; Stage 3, $p=0.014 ;$ Stage 4, $p=0.006$; Stage 5, $p=0.219$.

\section{Prevalence of MAU}

The incidence of MAU was $42.8 \%$ in the present study. This finding suggests that the early stage of CKD is often overlooked and therefore is clinically underdiagnosed. The reported prevalence of MAU in hypertensive populations exceeds that observed in the general population (12-14, 18-20). However, the prevalence of MAU in hypertensive patients is highly variable among studies, with a range of 26.6 to $58.4 \%(14,19,20)$.

Several factors can affect the results of investigations. Aging is recognized as an independent risk factor for renal disease resulting from glomerular ischemia secondary to renal blood flow changes that occur with age. In addition, it has been demonstrated that the prevalence of MAU increases with age $(13,14)$. The mean age of the present cohort was approximately 70 years, which was older than that evaluated in previous studies. A total of $38.4 \%$ of the enrolled population was diabetic, whereas other studies excluded diabetic patients $(21,22)$. Additionally, the prevalence of subjects with moderate or severe renal insufficiency, which is also a reported predictor of albuminuria, was as high as $31.9 \%$ among the total patient population. Furthermore, hypertensive patients with known atherosclerotic disease were included in the present study. Therefore, the current cohort is likely to represent hypertensive populations encountered in real-world practice. On the other hand, the mean blood pressure was $130.9 \pm 21.7 \mathrm{mmHg}$ in our cohort. In the iSERACH study, $58.4 \%$ of patients had albuminuria, and the 
Table 3. MAU and Patient Characteristics

\begin{tabular}{|c|c|c|c|}
\hline & MAU(-) & MAU(+) & $\mathrm{p}$ value \\
\hline Total number(\%) & $719(57.2)$ & $539(42.8)$ & \\
\hline age(years) & $68.3 \pm 11.3$ & $72.2 \pm 11.3$ & $<0.001$ \\
\hline male gender $(\%)$ & $468(65.2)$ & $285(53.0)$ & $<0.001$ \\
\hline height $(\mathrm{cm})$ & $161.5 \pm 9.2$ & $159.0 \pm 9.4$ & $<0.001$ \\
\hline body weight(kg) & $62.7 \pm 11.7$ & $60.6 \pm 12.4$ & 0.004 \\
\hline $\mathrm{BMI}\left(\mathrm{kg} / \mathrm{m}^{2}\right)$ & $23.9 \pm 3.3$ & $23.9 \pm 3.9$ & ${ }^{*} 0.802$ \\
\hline systolic $\mathrm{BP}(\mathrm{mmHg})$ & $129.3 \pm 12.2$ & $132.8 \pm 13.2$ & $<0.001$ \\
\hline diastolic $\mathrm{BP}(\mathrm{mmHg})$ & $74.9 \pm 8.9$ & $74.4 \pm 9.0$ & 0.335 \\
\hline diabetes mellitus & $224(49.6 \%)$ & $228(50.4 \%)$ & 0.851 \\
\hline \multicolumn{4}{|l|}{ laboratory findings } \\
\hline $\mathrm{eGFR}\left(\mathrm{ml} / \mathrm{min} / 1.73 \mathrm{~m}^{2}\right)$ & $67.1 \pm 17.7$ & $62.7 \pm 20.6$ & $<0.001$ \\
\hline AST(IU/L) & $23.8 \pm 12.0$ & $22.6 \pm 7.2$ & 0.044 \\
\hline ALT(IU/L) & $22.2 \pm 20.6$ & $20.9 \pm 22.0$ & 0.313 \\
\hline $\mathrm{BUN}(\mathrm{mg} / \mathrm{dL})$ & $16.7 \pm 8.6$ & $18.1 \pm 8.4$ & 0.009 \\
\hline $\mathrm{Cr}(\mathrm{mg} / \mathrm{dL})$ & $0.87 \pm 0.52$ & $0.94 \pm 0.55$ & 0.004 \\
\hline Glucose (mg/dL) & $113 \pm 36$ & $119 \pm 40$ & 0.016 \\
\hline HbA1c(JDS) & $5.59 \pm 0.71$ & $5.83 \pm 0.87$ & $<0.001$ \\
\hline \multicolumn{4}{|l|}{ medication } \\
\hline \multicolumn{4}{|l|}{ no medication } \\
\hline single CB & $57.4 \%$ & $42.6 \%$ & 0.059 \\
\hline single ARB & $61.7 \%$ & $38.3 \%$ & 0.001 \\
\hline single ACEI & $70.7 \%$ & $29.3 \%$ & 0.008 \\
\hline single diuretics & $50.0 \%$ & $50.0 \%$ & $* * 1.000$ \\
\hline single $B$ blocker & $66.7 \%$ & $33.3 \%$ & 0.157 \\
\hline Single combination drug & $78.6 \%$ & $21.4 \%$ & 0.033 \\
\hline \multicolumn{4}{|l|}{ vascular events } \\
\hline IHD & $60.4 \%$ & $39.6 \%$ & 0.001 \\
\hline CVD & $55.6 \%$ & $44.4 \%$ & 0.378 \\
\hline PAD & $37.5 \%$ & $62.5 \%$ & 0.317 \\
\hline $\mathrm{IHD}+\mathrm{CVD}$ & $54.2 \%$ & $45.8 \%$ & 0.564 \\
\hline $\mathrm{IHD}+\mathrm{PAD}$ & $44.1 \%$ & $55.9 \%$ & 0.493 \\
\hline $\mathrm{IHD}+\mathrm{CVD}+\mathrm{PAD}$ & $37.5 \%$ & $62.5 \%$ & 0.317 \\
\hline
\end{tabular}

BMI: body mass index

*Welch $t$ test

BP: blood pressure

GFR: glomerular filtration rate

AST: aspartate aminotransferase

ALT: alanine aminotransferase

BUN: blood urea nitrogen

Cr: creatinine

JDS: Japan Diabetes Society

CB: calcium channel blocker

ARB: angiotensin II receptor blocker

ACEI: angiotensin converting enzyme inhibitor

**Fisher's exact test

IHD: ischemic heart disease

CVD: cerebrovascular disease

PAD: peripheral artery disease

Table 5. Multivariate Analysis for the Presence of MAU

\begin{tabular}{lccl}
\hline Factor & OR & $95 \%$ CI & p value \\
\hline Systolic BP & 1.026 & $1.012-1.041$ & $<0.001$ \\
HbA1c & 1.371 & $1.082-1.736$ & 0.009 \\
eGFR & 0.988 & $0.978-0.998$ & 0.016 \\
\hline
\end{tabular}

MAU: microalbuminuria

OR: odds ratio

CI: confidence interval

BP: blood pressure

GFR: glomerular filtration rate

mean blood pressure was $149.2 \pm 20.2 \mathrm{mmHg}$. In addition, a total of $76.8 \%$ of the uncontrolled hypertensive patients
Table 4. Univariate Analysis for Related Factors on MAU

\begin{tabular}{lccl}
\hline Variable & OR & $95 \%$ CI & $\mathrm{p}$ value \\
\hline Age & 1.030 & $1.019-1.042$ & $<0.001$ \\
Gender & 1.698 & $1.332-2.164$ & $<0.001$ \\
Height & 0.971 & $0.958-0.985$ & $<0.001$ \\
Body weight & 0.987 & $0.977-0.998$ & 0.018 \\
systolic BP & 1.025 & $1.015-1.035$ & $<0.001$ \\
diastolic BP & 1.003 & $0.991-1.016$ & 0.593 \\
eGFR & 0.988 & $0.981-0.995$ & $<0.001$ \\
BUN & 1.019 & $1.001-1.039$ & 0.044 \\
Glu & 1.004 & $1.001-1.008$ & 0.021 \\
HbA1c (JDS) & 1.449 & $1.197-1.753$ & $<0.001$ \\
DM & 1.620 & $1.284-2.044$ & $<0.001$ \\
PAD & 1.925 & $1.169-3.170$ & 0.010 \\
\hline
\end{tabular}

MAU: microalbuminuria

OR: odds ratio

CI: confidence interval

BP: blood pressure

GFR: glomerular filtration rate

BUN: blood urea nitrogen

JDS: Japan Diabetes Society

DM: diabetes mellitus

PAD: peripheral artery disease

were included (14). Therefore, an incidence of albuminuria of $42 \%$ in our relatively well-controlled hypertensive population suggests a remarkably high prevalence of MAU in current practice. Another possible explanation for this high value is methodological differences, including urine sample collection. Furthermore, the diagnostic criteria may have affected the outcomes in our series. Weir et al. reported an incidence of MAU of $40 \%$ among Asian hypertensive diabetic patients (23). Konta et al. also demonstrated a higher prevalence of MAU in the Japanese general population (13). Therefore, it is possible that Asian populations are susceptible to MAU.

\section{Risk factors of MAU}

The results of the present study also demonstrated that, among hypertensive patients, the risk of developing MAU is significantly greater if the patient also has a low eGFR. Age was not determined to be a risk factor of MAU in multiple regression analysis because it was considered a confounding factor. The eGFR value is calculated with age and serum creatinine levels, so age itself is a confounder for eGFR. This is the reason why age did not appear in the final multiple regression analysis results. These data suggest the presence of strong and independent influences of systemic arterial pressure on urinary albumin excretion, which is consistent with the findings of a recent report showing that the development of MAU is linked to insufficient blood pressure control in patients with essential hypertension $(24,25)$.

A relationship between obesity and urinary albumin excretion was reported in a large cross-sectional study, while a correlation between weight loss and decreased proteinuria has also been documented (26). Obesity affects the renal glomerular filtration rate, renal blood flow, and the development of renal hypertrophy and is known to have a negative impact on renal disease. Furthermore, Ramirez et al. re- 
ported a J-shaped relationship between BMI and the prevalence of proteinuria (18). In the present study, $30.6 \%$ of patients had a BMI $>25 \mathrm{~kg} / \mathrm{m}^{2}$, and the adjusted risk factors of MAU were unclear when BMI was considered as a continuous variable.

Recent investigations have demonstrated that strict blood pressure control reduces the level of proteinuria and prevents the progression of ESRD (11, 27-29). In this analysis, the mean systolic blood pressures of patients with positive and negative MAU results were $132.8 \pm 13.2 / 74.4 \pm 9.0 \mathrm{mmHg}$ and $129.3 \pm 12.2 / 74.9 \pm 8.9 \mathrm{mmHg}$, respectively. Therefore, the difference in the mean systolic blood pressure between the two groups was $3.5 \mathrm{mmHg}$. These findings confirm the importance of strictly controlling blood pressure to prevent glomerular injury. MAU was more frequently observed in men than women, which is consistent with a previous study reporting that men have a higher risk of developing ESRD and tend to develop ESRD earlier in life than women (30). Therefore, we performed a multiple logistic regression analysis adjusted for sex and CKD stages 1 and 2, and the identified risk factors remained the same. These findings strongly suggest that blood pressure and glucose levels should be managed more strictly in the early phase of hypertension.

It has been reported that certain classes of antihypertensive medications, such as ACEIs and ARBs, reduce proteinuria (21, 27-29). However, there were no clear differences in renal function preservation effects between drugs in this study. Because information regarding the dose and duration of prescribed medications and the duration of a hypertensive status was not available, we were unable to further assess the possibility of differences in the class effects of antihypertensive drugs.

Other important contributions to an increased prevalence of MAU were the comorbidities of PAD and diabetes. Murakami et al. demonstrated that the brachial-ankle pulse wave velocity is an independent risk factor for MAU (19). Diabetes is a well-known predictor of proteinuria, and it has been shown that strictly controlling glucose levels can reduce and prevent proteinuria $(26,31)$. These findings are consistent with the results of the present study. MAU was more frequently observed in patients with polyvascular disease. It has been demonstrated that a lower ankle-brachial index is associated with a greater risk of cardiovascular complications. Moreover, in the REACH registry, the incidence of future cardiovascular events was higher among patients with polyvascular disease than those with monovascular disease (32). Taken together, the proposed hypothesis that MAU is a marker of more generalized and widespread endothelial dysfunction and atherosclerosis is consistent with the findings of the present study. Moreover, the view that MAU is an independent risk factor for atherosclerotic disease and carries prognostic information beyond that of other risk factors is supported by our data. Therefore, clinicians should strive to achieve better control of the blood pressure and glucose levels to prevent MAU among patients seen in their daily practice.

\section{Limitations}

There are several limitations that should be considered. First, this was an observational study, and there may be selection bias in our study population. This somewhat limits the ability to generalize the present study outcomes; however, we enrolled consecutive outpatients, meaning our results are likely to represent actual findings. Second, the urinalyses were only performed once, which does not comply with the requirement for multiple urine collections to diagnose MAU (33). However, Brantsma et al. reported that a single measurement has sufficient power to predict future prognosis (34). Third, single measurements of UACR may overestimate the prevalence of MAU in patients with a low level of creatinine excretion, such as females and the elderly. Fourth, the eGFR values determined using the simplified prediction equation derived from the MDRD study might not have been sufficiently correct because they were based on single blood samples. However, this equation is considered to be the most precise (35). Finally, no information regarding the severity or duration of hypertension was obtained in the present study.

\section{Conclusion}

The present study showed that the prevalence of MAU among hypertensive patients was $42.8 \%$, even in those with relatively well controlled blood pressure. In addition, the risk factors for the presence of MAU include eGFR, systolic blood pressure, and HbAlc level. These findings suggest that a substantial number of patients with CKD have MAU. Early detection and awareness of this sensitive marker are quite important for the management of hypertensive patients in real-world practice.

\section{The authors state that they have no Conflict of Interest (COI).}

\section{Acknowledgement}

We appreciate the Association for the Establishment of Evidence in Interventions, which is operated as a non-profit organization, for providing financial support.

\section{References}

1. Ninomiya T, Kiyohara Y, Kubo M, et al. Chronic kidney disease and cardiovascular disease in a general Japanese population: the Hisayama study. Kidney Int 68: 228-236, 2005.

2. Foley RN, Parfrey PS, Sarnak MJ. Clinical epidemiology of cardiovascular disease in chronic renal disease. Am J Kidney Dis 32: S112-S119, 1998.

3. Levey AS, Beto JA, Coronado BE, et al. Controlling the epidemic of cardiovascular disease in chronic renal disease: what do we know? What do we need to learn? Where do we go from here? National Kidney Foundation Task Force on Cardiovascular Disease. Am J Kidney Dis 32: 853-906, 1998.

4. Culleton BF, Hermmelgan BR. Is chronic kidney disease a cardiovascular disease risk factor? Semin Dial 16: 95-100, 2003.

5. Sarnak MJ, Levey AS, Schoolwerth AC, et al; American Heart As- 
sociation Councils on Kidney in Cardiovascular Disease, High Blood Pressure Research, Clinical Cardiology, and Epidemiology and Prevention. Kidney disease as a risk factor for development of cardiovascular disease: a statement from the American Heart Association Councils on Kidney in Cardiovascular Disease, High Blood Pressure Research, Clinical Cardiology, and Epidemiology and Prevention. Circulation 108: 2154-2169, 2003.

6. Jager A, Kostense PJ, Ruhe HG, et al. Microalbuminuria and peripheral arterial disease are independent predictors of cardiovascular and all-cause mortality among hypertensive subjects; five-year follow-up of the Hoorn study. Atherioscler Thromb Vasc Biol 19: 617-624, 1999.

7. Rossing P, Hougaard P, Borch-Johnson K, Parving HH. Predictors of mortality in insulin dependent diabetes; 10 year observational follow up study. BMJ 313: 779-784, 1996.

8. Gerstein HC, Mann JF, Yi Q, et al. Hope study investigators. Albuminuria and risk of cardiovascular events, death, and heart failure in diabetic and nondiabetic individuals. JAMA 286: 421-426, 2001.

9. Morgensen CE. Microalbuminuria predicts clinical proteinuria and early mortality in muturity-onset diabetes. $\mathrm{N}$ Engl J Med 310: 356-360, 1984.

10. Hillege HL, Janssen WM, Bak AA, et al; Prevend Study Group. Micoralbuminuria is common, also in a nondiabetic, nonhypertensive population, and an independent indicator of cardiovascular risk factors and cardiovascular morbidity. J Intern Med 249: 519526, 2001.

11. Ibsen $\mathrm{H}$, Olsen $\mathrm{MH}$, Wachtell $\mathrm{K}$, et al. Reduction in albuminuria translates to reduction in cardiovascular events in hypertensive patients: losartan intervention for endpoint reduction in hypertension study. Hypertension 45: 198-202, 2005.

12. de Jong PE, Hillege HL, Pinto-Sietsma SJ, de Zeeum D. Screening for microalbuminuria in general population: a tool to detect subjects at risk for progressive renal failure in an early phase? Nephrol Dial Transplant 18: 10-13, 2003.

13. Konta T, Hao Z, Abiko $\mathrm{H}$, et al. Prevalence and risk factor analysis of microalbuminuria in Japanese general population: the Takahata study. Kidney Int 70: 751-756, 2006.

14. Böhm M, Thoenes M, Danchin N, Bramlage P, La Puerta P, Volpe M. Association of cardiovascular risk factors with microalbuminuria in hypertensive individuals: the i-SEARCH study. J Hypertens 25: 2317-2324, 2007.

15. Imai E, Horio M, Nitta $\mathrm{K}$, et al. Estimation of glomerular filtration rate by the MDRD study equation modified for Japanese patients with chronic kidney disease. Clin Exp Nephrol 11: 45-50, 2007.

16. Sasaki M, Pugla MJ, Parker DR, Kuromoto K, Furukawa I, Konishi I. Measurement of the albumin content of urinary protein using dipsticks. J Clin Lab Anal 13: 246-250, 1999.

17. Guh JY. Proteinuria versus albuminuria in chronic kidney disease. Nephrology 15: 53-56, 2010.

18. Tomura S, Kawada K, Saito K, et al. Prevalence of microalbuminuria and relationship to the risk of cardiovascular disease in Japanese population. Am J Nephrol 19: 13-20, 1999.

19. Murakata M, Nunokawa T, Yoshinaga K, Toyota T; J-TOPP Study Group. Brachial-ankle pulse was velocity is an independent risk factor for microalbuminuria in patients with essential hypertension: a Japanese trial on the prognostic implication of pulse wave velocity (J-TOPP). Hypertens Res 29: 515-521, 2006.

20. Boersma C, Postman MJ, Visser ST, et al; PREVEND Study
Group. Baseline albuminuria predicts the efficacy of blood pressure-lowering drugs in preventing cardiovascular events. Br J Clin Pharmacol 65: 723-732, 2008.

21. Brantsma AH, Atthobari J, Bakker SJ, de Zeeuw D, de Jong PE, Gansevoort RT. What predicts progression and regression of urinary albumin excretion in the nondiabetic population? J Am Soc Nephrol 18: 637-645, 2007.

22. Gatzka CD, Reid CM, Lux A, Dart AM, Jennings GL; Hypertension Diagnostic Service Investigators. Left ventricular mass and microalbuminuria: relation to ambulatory blood pressure. Clin Exp Pharmacol Physiol 26: 514-516, 1999.

23. Weir MR. Albuminuria predicting outcome in diabetes; incidence of microalbuminuria in Asian-Pacific Rim. Kidney Int 66: 538539, 2004.

24. Asselbergs FW, Diercks GFH, Hillege HL, et al. Prevention of renal and vascular endstage disease intervention trial (Prevent IT) investigators. Effects of fosinopril and pravastatin on cardiovascular events in subjects with microalbuminuria. Circulation 110: 2809-2816, 2004.

25. Pascual JM, Radilla E, Gozalez C, Pérez-Hoyos S, Redon J. Long-term impact of systolic blood pressure and glycemia on the development of microalbuminuria in essential hypertension. Hypertension 45: 1125-1130, 2005.

26. UK Prospective Diabetes Study Group. Tight blood pressure control and risk of macrovascular and microvascular complications in type 2 diabetes: UKPDS 38. BMJ 317: 703-713, 1998.

27. Yusuf S, Sleight G, Pogue J, Bosch J, Davies R, Dagenais G; The Heart Outcomes Prevention Evaluation Study Investigators. Effects of an angiotensin-converting-enzyme inhibitor, ramipril, on cardiovascular events in high-risk patients. N Engl J Med 342: 145-153, 2000.

28. Heart outcomes Prevention evaluation (HOPE) study investigators. Effect of ramipril on cardiovascular and microvascular outcomes in people with diabetes mellitus. Results of HOPE study and MICRO-HOPE substudy. Lancet 355: 253-259, 2000.

29. Parving HH, Lehnert H, Bröchner-Mortensen J, Gomis R, Andersen S, Arner P. The effect of irbesartan on the development of diabetic nephropathy in patients with type 2 diabetes. $\mathrm{N}$ Engl $\mathrm{J}$ Med 345: 870-878, 2001.

30. Hopper J Jr, Trew PA, Biava CG. Membranous nephropathy; its relative benignity in women. Nephron 29: 18-24, 1981.

31. The Diabetes Control and Complications Trial/Epidemiology of Diabetes Interventions and Complications Research Group. Retinopathy and nephropathy in patients with type 1 diabetes four years after a trial of intensive therapy. N Engl J Med 342: 381389,2000

32. Steg PG, Bhatt DL, Wilson PW, et al; REACH Registry Investigators. One-year cardiovascular event rates in outpatients with atherothrombosis. JAMA 297: 1197-1206, 2007.

33. Levey AS, Eckardt KU, Tsukamoto Y, et al. Definition and classification of chronic kidney disease: a position statement from Kidney Disease: Improving Global Outcomes (KDIGO). Kidney Int 67: 2089-2100, 2005.

34. Brantsma AH, Bakker SJ, de Zeeuw D, de Jong PE, Ganservoort RT; PREVENT Study Group. Extended prognosis value of urinary albumin excretion for cardiovascular events. J Am Soc Nephrol 19: 1785-1791, 2008.

35. Bakris G. Proteinuria; a rink to understanding changes in vascular compliance? Hypertension 46: 473-474, 2005.

(C) 2014 The Japanese Society of Internal Medicine http://www.naika.or.jp/imonline/index.html 